\title{
Venous Thrombosis at Unusual Sites and the Role of Thrombophilia
}

\author{
Federico Lussana, M.D., ${ }^{1,2}$ Francesco Dentali, M.D., ${ }^{3}$ Walter Ageno, M.D., ${ }^{3}$ \\ and Pieter W. Kamphuisen, M.D., Ph.D. 1
}

Thrombophilia includes multiple inherited and acquired risk factors that determine a shift in the balance of procoagulant and anticoagulant factors promoting hypercoagulability, which is associated with an increased risk of venous thromboembolism (VTE). VTE is characterized by more common clinical manifestations, such as deep vein thrombosis of the lower limbs or pulmonary embolism, and less common clinical manifestations affecting cerebral, splanchnic, upper limbs, and retinal veins. The role of inherited thrombophilia in the pathogenesis of VTE at unusual sites is better established in cerebral vein thrombosis, but its role is less clear in splanchnic, upper limbs, and retinal vein thrombosis, in which acquired risk factors such as malignancy, central venous catheters, or systemic diseases also are frequently involved. The complex interactions between different inherited and acquired thrombophilic risk factors and their relationship with endothelium may be considered the pathophysiologic key of underlying phenotypic manifestations of thrombosis. The understanding of these mechanisms might facilitate diagnosis with appropriate investigations and improve therapeutic decision making.

KEYWORDS: Thrombophilia, thrombosis of the upper extremities, retinal vein occlusion, cerebral vein thrombosis, splanchnic vein thrombosis

Venous thromboembolism (VTE) is a multifactorial disease in which multiple inherited and acquired risk factors act synergistically determining different thrombotic manifestations. Although thrombosis can potentially involve any section of the venous system, common manifestations of VTE are deep vein thrombosis (DVT) of the lower limbs and pulmonary embolism. Uncommon manifestations of VTE affect atypical sites, such as cerebral sinus, splanchnic, upper limbs, and retinal veins. Different thrombotic manifestations can result from different inherited and acquired thrombophilic states. For example, the antiphospholi-

${ }^{1}$ Department of Vascular Medicine, Academic Medical Center, University of Amsterdam, Amsterdam, The Netherlands; ${ }^{2}$ Unit of Hematology and Thrombosis Department of Medicine, Surgery and Dentistry Ospedale San Paolo, University of Milano, Milano, Italy; ${ }^{3}$ Department of Clinical Medicine, University of Insubria, Varese, Italy.

Address for correspondence and reprint requests: Federico Lussana, M.D., Department of Vascular Medicine, Academic Medical Center, pid syndrome is associated with placenta thrombosis, ${ }^{1}$ myeloproliferative disorders are associated with abdominal vein thrombosis, ${ }^{2}$ and the prothrombin mutation G20210A (PTM) increases the risk of lower limb thrombosis, portal vein thrombosis (PVT) and cerebral vein thrombosis (CVT) ${ }^{3,4}$ In the complex pathophysiology of different phenotypic manifestations of thrombosis, even the endothelium might play a critical role by acquiring in response to different signals procoagulant and anticoagulant properties that could be expressed differently throughout the vascular tree. ${ }^{5}$ In recent years, it became clear that congenital and acquired

University of Amsterdam, Meibergdreef 91105 AZ Amsterdam, The Netherlands (e-mail: federico.lussana@ao-sanpaolo.it).

Thrombophilia in Clinical Practice; Guest Editors, Saskia Middeldorp, M.D., Ph.D., and Marcel Levi, M.D., Ph.D.

Semin Thromb Hemost 2007;33:582-587. Copyright (C) 2007 by Thieme Medical Publishers, Inc., 333 Seventh Avenue, New York, NY 10001, USA. Tel: +1(212) 584-4662.

DOI 10.1055/s-2007-985754. ISSN 0094-6176. 
thrombophilia through complex interactions with the vessel wall may induce alterations in the hemostatic balance that predispose to thrombosis at unusual sites. However, despite reasonable evidence that different risk factors could lead to specific clinical manifestations of VTE, most of these observations were derived from small studies because of the relative rarity of thrombotic events at unusual sites.

This review article focuses on the role of thrombophilia in the pathogenesis of unusual sites of VTE. The interactions among different risk factors and the strength of their associations in this field are also discussed.

\section{THROMBOSIS OF THE UPPER EXTREMITIES}

The incidence of upper extremities deep vein thrombosis (UEDVT) is $\sim 10 \%$ of the total incidence of venous thrombosis. ${ }^{6}$ UEDVT can be classified into different categories according to its etiology: idiopathic, including Paget-Schroetter syndrome or effort syndrome; and secondary, in which a trigger or underlying disorder such as indwelling intravenous catheters or neoplasms can be identified. The clinical importance of UEDVT has increased in recent years mainly due to the increasing use of central venous catheters (CVCs), which are an important risk factor. Until a decade ago, the prevalence was low, with an estimated range from $1 \%$ to $4 \%{ }^{7}$ Idiopathic UEDVT accounts for $\sim 10$ to $30 \%$ of all cases, ${ }^{8,9}$ and strenuous muscular effort is detected in one fourth of primary cases. ${ }^{10}$ The Paget-Schroetter syndrome or effort syndrome is a pinching of the axillary-subclavian vein at the thoracic outlet by muscular and osteo-tendinous structures induced by abduction and extension of the arm determining a mechanical obstruction. The compression of the axillary-subclavian vein is physiologic but it may be aggravated by anatomical abnormalities or by repetitive compression, given that it usually happens during sports or occupational activities, leading to endothelial damage and inflammation $^{11}$ and to the development of venous thrombosis. This form of UEDVT is frequently reported in athletes ${ }^{12}$ and patients usually are apparently healthy young males. ${ }^{13,14}$

The prevalence of inherited thrombophilia in patients with primary UEDVT ranges from $10 \%$ to 20\%. ${ }^{9,10,13-15}$ Martinelli et $\mathrm{al}^{10}$ showed after multivariate analysis a 5- to 6-fold increased risk for factor $\mathrm{V}$ Leiden mutation (FVL) and PTM, respectively, and a 5-fold increased risk for natural inhibitors (antithrombin, protein $\mathrm{C}$, and protein $\mathrm{S}$ deficiency) considered together, whereas there was no association with hyperhomocysteinemia. Blom et $\mathrm{al}^{9}$ found a 3 -fold increased risk for the combination of FVL and PTM. In line with these studies, two small studies with 51 and 31 consecutive patients, respectively, also found a high prevalence of thrombophilic defects in UEDVT patients. ${ }^{13,14}$ For patients with a history of strenuous muscular effort the association with thrombophilia is less clear, but this could be due to the small size of the studies..$^{10,13,14}$ The presence of antiphospholipid antibodies in patients with primary UEDVT varies from 8 to $31 \%,{ }^{10,13-15}$ but it is approximately $8 \%$ in two studies with a larger series of patients. ${ }^{10,15}$ Another important risk factor for apparently idiopathic UEDVT is an occult malignancy, which can be diagnosed in about one fourth of cases within 1 year of follow-up. ${ }^{16}$

Secondary cases of UEDVT are more common than primary cases and are more frequent in older and hospitalized patients. ${ }^{6,8,14,17}$ The most important risk factors are the presence of CVC (accounting for up to $70 \%$ of secondary cases), $, 8,9,17,18$ and cancer (diagnosed in up to $61 \%$ of cases). ${ }^{8,9,17-19}$ The presence of FVL and PTM mutations seems to increase the risk of CVCrelated thrombosis, with an odds ratio (OR) of 2.7 (95\% confidence interval [CI], 1.9 to 3.8$).{ }^{20}$ Different studies showed a synergistic effect in increasing the risk of UEDVT between oral contraceptives (OCs) and thrombophilia of up to 9-fold (95\% CI, 2.8 to 30.2). ${ }^{9,10,15} \mathrm{~A}$ recent review reported an important link between UEDVT and pregnancies achieved with the use of assisted reproductive techniques in which the higher incidence of thrombosis involving the internal jugular vein $(81 \%)$ has not yet been understood. ${ }^{21}$ Inherited thrombophilia was detected in $41 \%$ of these women, but the limitation is that these data are derived mainly from case reports. ${ }^{21}$

The decision to carry out routine testing for inherited thrombophilia among patients with an episode of either primary or secondary UEDVT is controversial for at least two reasons: (1) the increased risk of recurrence determined by thrombophilia is not well known and it seems to be modest ${ }^{10}$; and (2) clinical implications of thrombophilia such as prophylactic or optimal duration of anticoagulation are unknown. Considering the possible synergistic effects between genetic thrombophilia and environmental risk factors, such as OCs, young patients with unexplained or hormone-related DVT could be advised about screening for thrombophilia.

\section{RETINAL VEIN OCCLUSION}

Retinal vein occlusion (RVO) is a paradigm of complexity of VTE that results from multiple and synergistic risk factors, including local factors and systemic diseases, that determine the thrombogenic conditions of the Virchow's triad, such as stasis, vessel wall damage, and hypercoagulability. RVO is the most common vascular disease of the eye and is the main cause of visual loss after diabetes. The incidence rate of RVO is $\sim 0.5$ per 1,000 persons older than 40 years and increases significantly 
with age, ${ }^{22}$ with more than $50 \%$ of patients older than 65 years. ${ }^{23} \mathrm{RVO}$ can be classified accordingly to the site of occlusion into branch RVO, hemicentral RVO, and central retinal vein occlusion (CRVO). CRVO affects the venous flow of the entire retina, determining a more severe clinical picture. Local risk factors of RVO include open-angle glaucoma, ocular hypertension (which affects up to $43 \%$ of patients), and local inflammation. ${ }^{24}$ An anatomical factor involved in the pathophysiology of $\mathrm{RVO}$ is the course of the vessels through the lamina cribrosa, which can degenerate with aging, causing a mechanical obstruction leading to endothelial damage. Systemic diseases associated with a higher incidence of $\mathrm{RVO}$ are hypertension, diabetes, dyslipidemia, increased blood viscosity, and cardiovascular diseases. ${ }^{25-29}$ The potential role of thrombophilia in the development of RVO is still unclear, with conflicting results in the literature; however, it seems to be marginal. A recent meta-analysis ${ }^{30}$ assessed the prevalence of thrombophilia among patients with RVO. The included studies often were retrospective, with a limited number of patients. FVL was evaluated in 14 case-control studies and had an overall OR for RVO of 1.5 (95\% CI, 1.0 to 3.2). ${ }^{30} \mathrm{In}$ most studies the incidence of FVL was not significantly higher in patients with RVO. The role of PTM in RVO also seemed marginal (OR, 1.6; $95 \% \mathrm{CI}, 0.8$ to 1.6$).{ }^{30} \mathrm{In}$ five studies, none of the patients and in one study none of the controls were carriers of PTM. ${ }^{30}$ Deficiencies of natural inhibitors were scarce and not associated significantly with RVO. ${ }^{30}$ Hyperhomocysteinemia had an overall OR of 8.9 (95\% CI, 5.7 to 13.7), derived from 11 studies that included a total of 527 cases and 955 controls. ${ }^{30}$ Thermolabile variant of methylenetetrahydrofolate reductase (MTHFR) was not associated with RVO (overall OR, 1.2; $95 \%$ CI, 0.9 to 1.6 ). ${ }^{30}$ The overall OR for combined anticardiolipin immunoglobu$\operatorname{lin}(\mathrm{Ig}) \mathrm{M}$ and $\mathrm{IgG}$ from seven case-control studies was 3.9 (95\% CI, 2.3 to 6.7), whereas the role of lupus anticoagulant was unclear. ${ }^{30}$ Table 1 reports the main results found in Janssen meta-analysis. ${ }^{30}$

A study of 234 consecutive patients with RVO confirmed that the frequency of FVL was similar between cases and controls, with a slight increased prevalence in the subgroup of patients younger than 60 years. ${ }^{31}$ In the same study, the prevalence of PTM was not significantly different between cases and controls. ${ }^{31}$ In line with the aforementioned meta-analysis, a large cross-sectional study confirmed the association between high plasma homocysteine levels and RVO in patients younger than 70 years, with an OR of 3.76 (95\% CI, 1.06 to 13.40). ${ }^{32}$ In contrast, two recent case-control studies failed to demonstrate an association between increased levels of homocysteine and RVO. ${ }^{33,34}$

In conclusion, the role of thrombophilia in RVO is unclear and therefore routine testing for the presence of genetic thrombophilia is probably not advisable. Increased plasma levels of homocysteine may be an important risk factor, but this may reflect systemic inflammation, which is associated with cardiovascular risk factors. Atherosclerotic risk factors, such as hypertension and diabetes, play an important role in the development of RVO, and recently, RVO has been associated with a more than 2 -fold increased risk of cardiovascular mortality. ${ }^{35}$

\section{CEREBRAL VEIN THROMBOSIS}

CVT is a rather uncommon disease. However, thanks to the general availability of noninvasive techniques, in the last few years CVT is diagnosed more frequently, and less clinically severe cases of CVT are detected. In previous studies, the majority of CVTs were found to be secondary to local or systemic infections, and more than $30 \%$ of cases of CVT were considered idiopathic. ${ }^{36,37}$ However, more recent studies reported other risk factors, such as thrombophilia or the use of OCs to be associated with CVT. ${ }^{38,39}$

The prevalence of thrombophilic abnormalities in patients with CVT has been evaluated only in small studies and the results are often conflicting or not conclusive. Our group recently has published a systematic review and a meta-analysis of the studies that analyzed the association between CVT and the most frequent thrombophilic conditions. ${ }^{4} \mathrm{~A}$ total of 17 studies were included in the analysis. We found a strong association between both FVL and the PTM, and CVT. In detail, 13 studies including 469 cases and 3023 controls evaluated the role of FVL and nine studies including 360 cases and 2688 controls evaluated the role of PTM in patients with CVT. FVL was associated with

Table 1 Summary of the Results of the Meta-Analysis on Association between Thrombophilia and RVO ${ }^{30}$

\begin{tabular}{|c|c|c|c|c|}
\hline Thrombophilic Abnormality & OR (95\% Cl) & $\begin{array}{l}\text { No. of Included } \\
\text { Studies }\end{array}$ & $\begin{array}{l}\text { No. of } \\
\text { Cases }\end{array}$ & $\begin{array}{l}\text { No. of } \\
\text { Controls }\end{array}$ \\
\hline Factor V Leiden & $1.5(1.0-2.2)$ & 14 & 792 & 1418 \\
\hline G20210A mutation of prothrombin & $1.6(0.8-3.2)$ & 12 & 700 & 1334 \\
\hline Hyperhomocysteinemia & $8.9(5.7-13.7)$ & 11 & 527 & 955 \\
\hline MTHFR & $1.2(0.9-1.6)$ & 10 & 581 & 1080 \\
\hline Anticardiolipin antibodies & $3.9(2.3-6.7)$ & 7 & 412 & 508 \\
\hline
\end{tabular}

RVO, retinal vein occlusion; OR, odds ratio; $\mathrm{Cl}$, confidence interval; MTHFR, thermolabile variant of methylenetetrahydrofolate reductase. 
CVT, with an OR of 3.38 (95\% CI, 2.27 to 5.05); PTM was associated with CVT, with an OR of 9.27 (95\% CI, 5.85 to 14.67$)$. We also found an equally strong association between CVT and hyperhomocysteinemia (OR, $4.07 ; 95 \%$ CI, 2.54 to 6.52 ), although only four studies were actually retrieved.

Data on antiphospholipid antibodies syndrome and on deficiencies of antithrombin, protein $\mathrm{C}$, and protein $\mathrm{S}$ were inadequate to allow any conclusions. Two studies analyzed the role of deficiencies of antithrombin, protein $\mathrm{C}$, and protein $\mathrm{S}$ as risk factors for CVT. ${ }^{40,41}$ The combined OR of the two studies was 2.69 for antithrombin (95\% CI, 0.66 to 10.96), 11.10 for protein C (95\% CI, 1.87 to 66.05$)$, and 12.49 for protein S (95\% CI, 1.45 to $107.29 ; p=0.03) .{ }^{40,41}$ Because of the low number of eligible patients, the confidence intervals are very wide. Only one study considered antiphospholipid syndrome ${ }^{40}$ and one study included anticardiolipin antibodies alone. ${ }^{42}$ In the first study, ${ }^{40}$ the prevalence of antiphospholipid antibodies was higher in CVT patients (nine of 121) compared with controls (zero of 242). In the second study, ${ }^{42}$ the authors found a significantly higher incidence of positive anticardiolipin antibodies in CVT patients (seven of 31) in comparison with controls (one of 31; OR, 8.75; 95\% CI, 1.01 to 75.64). Table 2 summarizes the results of the aforementioned metaanalysis. ${ }^{4}$

The risk of CVT in women of reproductive age taking OCs and with concomitant thrombophilic conditions was evaluated in two studies. ${ }^{40,43}$ Martinelli et $\mathrm{al}^{40}$ found an OR of 19.5 (95\% CI, 5.7 to 67.3 ) in the presence of hyperhomocysteinemia, an OR of 30.0 ( $95 \% \mathrm{CI}, 3.4$ to 263.0 ) in the presence of FVL mutation, and an OR of 79.3 (95\% CI, 10.0 to 629.4) in the presence of PTM as compared with control women without any thrombophilic condition. A similar result was observed in a study performed by Gadelha et al, ${ }^{43}$ in which a multivariate analysis proved the independent association between CVT, PTM, and the use of OCs.

The role of other thrombophilic abnormalities was investigated in CVT patients in recent studies. Bugnicourt et $\mathrm{al}^{44}$ found significantly higher levels of factor VIII and von Willebrand factor in 16 CVT patients in comparison with controls. Conversely, Lichy et al found no significant association between CVT and a single nucleotide polymorphism of the thrombin activatable fibrinolysis inhibitor, and between CVT and the protein $\mathrm{Z}$ gene mutation (intron F G79A), which is linked with low protein $Z$ levels. ${ }^{45}$

In conclusion, CVT appears to be strongly associated with the FVL mutation, with the PTM G20210A, and with hyperhomocysteinemia. The role of the other thrombophilic abnormalities in the pathogenesis of CVT remains to be clarified.

\section{SPLANCHNIC VEIN THROMBOSIS}

Splanchnic vein thrombosis (SVT) is an uncommon but potentially life-threatening disease. Mesenteric vein thrombosis (MVT), PVT, and Budd-Chiari syndrome (BCS) are three autonomous diseases, but the involvement of two or more different abdominal vein segments is common.

Because symptoms are nonspecific, diagnosis of SVT is difficult and its true incidence is likely underestimated. However, advances in imaging techniques, especially Doppler ultrasonography and computed tomography, have facilitated its early diagnosis. Acquired causes of SVT vary according to the site of thrombosis. For MVT, the most common causes are cancer, intraabdominal inflammatory conditions (pancreatitis, abscess, inflammatory bowel disease, diverticulitis), postoperative state, liver cirrhosis, and portal hypertension. ${ }^{46}$ For PVT, the most common causes are included liver cirrhosis, hepatocellular carcinoma, and myeloproliferative disorders. ${ }^{47}$

Only few studies have examined the role of thrombophilia in patients with SVT. Janssen et al performed a case-control study in which they investigated the prevalence of FVL, PTM, and of inherited deficiencies of protein $\mathrm{C}$, protein $\mathrm{S}$, and antithrombin in 43 patients with BCS, in 92 patients with PVT, and in 474 population-based controls. ${ }^{48}$ Among the BCS patients, FVL (OR, 11.3; 95\% CI, 4.8 to 26.5) and

Table 2 Summary of the Results of the Meta-Analysis on Association between Thrombophilia and CVT

\begin{tabular}{|c|c|c|c|c|}
\hline Thrombophilic Abnormality & OR (95\% Cl) & $\begin{array}{l}\text { No. of Included } \\
\text { Studies }\end{array}$ & $\begin{array}{l}\text { No. of } \\
\text { Cases }\end{array}$ & $\begin{array}{l}\text { No. of } \\
\text { Controls }\end{array}$ \\
\hline Factor V Leiden & $3.38(1.27-5.05)$ & 13 & 469 & 3023 \\
\hline G20210A mutation of prothrombin & $9.27(5.85-14.67)$ & 9 & 360 & 2688 \\
\hline Hyperhomocysteinemia & $4.07(2.54-6.52)$ & 4 & 222 & 472 \\
\hline Protein C & $11.10(1.87-66.05)$ & 2 & 147 & 362 \\
\hline Protein S & $12.49(1.45-107.29)$ & 2 & 147 & 362 \\
\hline Antithrombin & $2.69(0.66-10.96)$ & 2 & 172 & 362 \\
\hline Antiphospholipid antibodies syndrome & $40.96(2.36-709.87)$ & 1 & 121 & 242 \\
\hline Anticardiolipin antibodies & $8.75(1.01-75.64)$ & 1 & 31 & 31 \\
\hline
\end{tabular}

$\mathrm{CVT}$, cerebral vein thrombosis; $\mathrm{OR}$, odds ratio; $\mathrm{Cl}$, confidence interval. 
inherited deficiency of protein C (OR, 6.8; 95\% CI, 1.9 to 24.4) were more prevalent than in controls, whereas the prevalence of PTM was not different in comparison to controls and no patient had an inherited deficiency of protein S or antithrombin. Similarly, among the PVT patients, FVL (OR, 2.7; 95\% CI, 1.1 to 6.9) and inherited deficiency of protein C (OR, 4.6; 95\% CI, 1.5 to 14.1$)$ were again more prevalent than in controls, whereas the prevalence of PTM and of inherited deficiency of protein $\mathrm{S}$ or antithrombin was not different in comparison to controls. The use of OCs was an important acquired risk factor for both BCS and PVT, given that 12 of $20 \mathrm{BCS}$ women (60\%) and 12 of 25 PVT women (48\%) between 15 and 49 years had been using OCs at the time of diagnosis in comparison to 65 of 169 controls (38\%). In another recent study, Primignani et $\mathrm{al}^{3}$ evaluated the prevalence of FVL, PTM, hyperhomocysteinemia, and deficiency of protein $\mathrm{C}$, protein $\mathrm{S}$, and antithrombin in 65 patients with extrahepatic portal vein obstruction and in 700 healthy controls. They found an association among PTM (OR, 8.1; 95\% CI, 3.8 to 17.5), deficiency of protein $C$, protein $S$, or antithrombin taken together (OR, 4.5; 95\% CI, 1.1 to 18.0 ), and portal vein obstruction, whereas the prevalence of hyperhomocysteinemia was not different in comparison to controls. In contrast to the study conducted by Janssen, ${ }^{48}$ the prevalence of FVL was not different between cases and controls, and the use of OCs was not associated with an increased risk of portal vein obstruction, given that $\mathrm{OCs}$ were used in a similar proportion of patients and controls (26\% and $28 \%$, respectively). Recently, Amitrano et al ${ }^{49}$ evaluated the prevalence of common thrombophilic abnormalities in 12 patients with MVT and in 431 healthy controls. FVL (OR, 6.2; 95\% CI, 1.6 to 24.5), PTM (OR, 6.9; 95\% CI, 1.7 to 27.3), and MTHFR TT677 genotype (OR, 4.5; 95\% CI, 1.4 to 14.4) were associated with an increased risk of MVT, whereas anticardiolipin antibodies, lupus anticoagulant, and deficiency of protein $\mathrm{C}$, protein $\mathrm{S}$, and antithrombin were not.

In conclusion, the results of these studies seem to suggest a potential role of thrombophilic abnormalities in the pathogenesis of SVT. However, the role of a single thrombophilic abnormality cannot be assessed because the prevalence and the role of these factors in patients with SVT have been evaluated only in small studies and the results are often conflicting or inconclusive.

\section{REFERENCES}

1. Infante-Rivard C, David M, Gauthier R, Rivard GE. Lupus anticoagulants, anticardiolipin antibodies, and fetal loss. A case-control study. N Engl J Med 1991;325:1063-1066

2. De Stefano V, Fiorini A, Rossi E, et al. Incidence of the JAK2 V617F mutation among patients with splanchnic or cerebral venous thrombosis and without overt chronic myeloproliferative disorders. J Thromb Haemost 2007;5: 708-714

3. Primignani M, Martinelli I, Bucciarelli P, et al. Risk factors for thrombophilia in extrahepatic portal vein obstruction. Hepatology 2005;41:603-608

4. Dentali F, Crowther M, Ageno W. Thrombophilic abnormalities, oral contraceptives, and risk of cerebral vein thrombosis: a meta-analysis. Blood 2006;107:2766-2773

5. Rosenberg RD, Aird WC. Vascular-bed-specific hemostasis and hypercoagulable states. N Engl J Med 1999;340:15551564

6. Joffe HV, Kucher N, Tapson VF, Goldhaber SZ. Upperextremity deep vein thrombosis: a prospective registry of 592 patients. Circulation 2004;110:1605-1611

7. Hill SL, Berry RE. Subclavian vein thrombosis: a continuing challenge. Surgery 1990;108:1-9

8. Mustafa S, Stein PD, Patel KC, Otten TR, Holmes R, Silbergleit A. Upper extremity deep venous thrombosis. Chest 2003;123:1953-1956

9. Blom JW, Doggen CJ, Osanto S, Rosendaal FR. Old and new risk factors for upper extremity deep venous thrombosis. J Thromb Haemost 2005;3:2471-2478

10. Martinelli I, Battaglioli T, Bucciarelli P, Passamonti SM, Mannucci PM. Risk factors and recurrence rate of primary deep vein thrombosis of the upper extremities. Circulation 2004;110:566-570

11. Nemcek AA Jr. Upper extremity deep venous thrombosis: interventional management. Tech Vasc Interv Radiol 2004; 7:86-90

12. Zell L, Kindermann W, Marschall F, Scheffler P, Gross J, Buchter A. Paget-Schroetter syndrome in sports activitiescase study and literature review. Angiology 2001;52:337-342

13. Hendler MF, Meschengieser SS, Blanco AN, et al. Primary upper-extremity deep vein thrombosis: high prevalence of thrombophilic defects. Am J Hematol 2004;76:330-337

14. Heron E, Lozinguez O, AlhencGelas M, Emmerich J, Fiessinger JN. Hypercoagulable states in primary upperextremity deep vein thrombosis. Arch Intern Med 2000;160 382-386

15. Vaya A, Mira Y, Mateo J, et al. Prothrombin G20210A mutation and oral contraceptive use increase upper-extremity deep vein thrombotic risk. Thromb Haemost 2003;89:452-457

16. Girolami A, Prandoni P, Zanon E, Bagatella P, Girolami B. Venous thromboses of upper limbs are more frequently associated with occult cancer as compared with those of lower limbs. Blood Coagul Fibrinolysis 1999;10:455-457

17. Hingorani A, Ascher E, Markevich N, et al. Risk factors for mortality in patients with upper extremity and internal jugular deep venous thrombosis. J Vasc Surg 2005;41:476478

18. Marinella MA, Kathula SK, Markert RJ. Spectrum of upperextremity deep venous thrombosis in a community teaching hospital. Heart Lung 2000;29:113-117

19. Schmittling ZC, McLafferty RB, Bohannon WT, Ramsey DE, Hodgson KJ. Characterization and probability of upper extremity deep venous thrombosis. Ann Vasc Surg 2004;18: 552-557

20. Van Rooden CJ, Rosendaal FR, Meinders AE, Van Oostayen JA, Van Der Meer FJ, Huisman MV. The contribution of factor V Leiden and prothrombin G20210A mutation to the risk of central venous catheter-related thrombosis. Haematologica 2004;89:201-206 
21. Chan WS, Ginsberg JS. A review of upper extremity deep vein thrombosis in pregnancy: unmasking the 'ART' behind the clot. J Thromb Haemost 2006;4:1673-1677

22. David R, Zangwill L, Badarna M, Yassur Y. Epidemiology of retinal vein occlusion and its association with glaucoma and increased intraocular pressure. Ophthalmologica 1988;197: 69-74

23. Hayreh SS, Zimmerman MB, Podhajsky P. Incidence of various types of retinal vein occlusion and their recurrence and demographic characteristics. Am J Ophthalmol 1994; 117:429-441

24. Prisco D, Marcucci R, Bertini L, Gori AM. Cardiovascular and thrombophilic risk factors for central retinal vein occlusion. Eur J Intern Med 2002;13:163-169

25. Hayreh SS, Zimmerman B, McCarthy MJ, Podhajsky P. Systemic diseases associated with various types of retinal vein occlusion. Am J Ophthalmol 2001;131:61-77

26. Mitchell P, Smith W, Chang A. Prevalence and associations of retinal vein occlusion in Australia. The Blue Mountains Eye Study. Arch Ophthalmol 1996;114:1243-1247

27. Dodson PM, Galton DJ, Hamilton AM, Blach RK. Retinal vein occlusion and the prevalence of lipoprotein abnormalities. Br J Ophthalmol 1982;66:161-164

28. Quinlan PM, Elman MJ, Bhatt AK, Mardesich P, Enger C. The natural course of central retinal vein occlusion. Am J Ophthalmol 1990;110:118-123

29. Cugati S, Wang JJ, Rochtchina E, Mitchell P. Ten-year incidence of retinal vein occlusion in an older population: the Blue Mountains Eye Study. Arch Ophthalmol 2006;124: 726-732

30. Janssen MC, den Heijer M, Cruysberg JR, Wollersheim H, Bredie SJ. Retinal vein occlusion: a form of venous thrombosis or a complication of atherosclerosis? A metaanalysis of thrombophilic factors. Thromb Haemost 2005;93: 1021-1026

31. Arsene S, Delahousse B, Regina S, Le Lez ML, Pisella PJ, Gruel Y. Increased prevalence of factor V Leiden in patients with retinal vein occlusion and under 60 years of age. Thromb Haemost 2005;94:101-106

32. Chua B, Kifley A, Wong TY, Mitchell P. Homocysteine and retinal vein occlusion: a population-based study. Am J Ophthalmol 2005;139:181-182

33. McGimpsey SJ, Woodside JV, Bamford L, et al. Retinal vein occlusion, homocysteine, and methylene tetrahydrofolate reductase genotype. Invest Ophthalmol Vis Sci 2005;46: $4712-4716$

34. Pinna A, Carru C, Zinellu A, Dore S, Deiana L, Carta F. Plasma homocysteine and cysteine levels in retinal vein occlusion. Invest Ophthalmol Vis Sci 2006;47:4067-4071
35. Cugati S, Wang JJ, Knudtson MD, et al. Retinal vein occlusion and vascular mortality: pooled data analysis of 2 population-based cohorts. Ophthalmology 2007;114:520524

36. Ameri A, Bousser MG. Cerebral venous thrombosis. Neurol Clin 1992;10:87-111

37. Gates PC. Cerebral venous thrombosis. A retrospective review. Aust N Z J Med 1986;16:766-770

38. Ferro JM, Canhao P, Stam J, Bousser MG, Barinagarrementeria F. Prognosis of cerebral vein and dural sinus thrombosis: results of the International Study on Cerebral Vein and Dural Sinus Thrombosis (ISCVT). Stroke 2004;35:664-670

39. de Bruijn SF, Stam J. Randomized, placebo-controlled trial of anticoagulant treatment with low-molecular-weight heparin for cerebral sinus thrombosis. Stroke 1999;30:484488

40. Martinelli I, Battaglioli T, Pedotti P, Cattaneo M, Mannucci PM. Hyperhomocysteinemia in cerebral vein thrombosis. Blood 2003;102:1363-1366

41. Bombeli T, Basic A, Fehr J. Prevalence of hereditary thrombophilia in patients with thrombosis in different venous systems. Am J Hematol 2002;70:126-132

42. Christopher R, Nagaraja D, Dixit NS, Narayanan CP. Anticardiolipin antibodies: a study in cerebral venous thrombosis. Acta Neurol Scand 1999;99:121-124

43. Gadelha T, Andre C, Juca AA, Nucci M. Prothrombin 20210A and oral contraceptive use as risk factors for cerebral venous thrombosis. Cerebrovasc Dis 2005;19:49-52

44. Bugnicourt JM, Roussel B, Tramier B, Lamy C, Godefroy O. Cerebral venous thrombosis and plasma concentrations of factor VIII and von Willebrand factor: a case-control study. J Neurol Neurosurg Psychiatry 2007;78:699-701

45. Lichy C, Dong-Si T, Reuner K, et al. Risk of cerebral venous thrombosis and novel gene polymorphisms of the coagulation and fibrinolytic systems. J Neurol 2006;253:316-320

46. Kumar S, Sarr MG, Kamath PS. Mesenteric venous thrombosis. N Engl J Med 2001;345:1683-1688

47. Valla DC, Condat B. Portal vein thrombosis in adults: pathophysiology, pathogenesis and management. J Hepatol 2000;32:865-871

48. Janssen HL, Meinardi JR, Vleggaar FP, et al. Factor V Leiden mutation, prothrombin gene mutation, and deficiencies in coagulation inhibitors associated with Budd-Chiari syndrome and portal vein thrombosis: results of a casecontrol study. Blood 2000;96:2364-2368

49. Amitrano L, Brancaccio V, Guardascione MA, et al. High prevalence of thrombophilic genotypes in patients with acute mesenteric vein thrombosis. Am J Gastroenterol 2001;96: 146-149 